\title{
Experimental Research on AA 6061/SICP Composites
}

\author{
E Vetre Selvan, K.Hariharan, V. Jayasurya, S. Jaiganesh, M.V. Kaviselvan
}

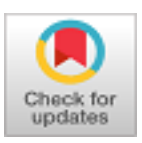

\begin{abstract}
Aluminium alloys are widely used in aerospace and automobile industries due to high strength to low weight ratio and their good mechanical properties such as better corrosion resistance and wear resistance, low thermal expansion as compared with other metals. The main objective of our work is to improve the mechanical properties such as impact strength, hardness of Aluminium based Metal Matrix Composite (MMC), and its relation with processing of the silicon carbide particulate (SiCp) as reinforced in Aluminum matrix. AA6061 alloy is chosen as matrix alloy, in which Aluminum is the base element. The work has been proposed for four different weight proportions of SiCp to aluminium matrix and the processing of the metal matrix composite is to be processed with stir casting setup and heat treated.
\end{abstract}

Keywords : AA6061; Silicon carbide; Casting; Mechanical Properties.

\section{INTRODUCTION}

$\mathrm{A}_{1}$ particulate fortresses are normally compelled to encompassing temperature applications because of the colossal perplex in higher temperature quality between the aluminum framework (low quality) and the particle support (high caliber) [1]. Another issue with aluminum based metal cross section composites is the issue of conveying a bond between the system and the fortifying stage [2]. To make such a bond, it is when in doubt essential to vacuum hot press the material at temperatures higher than the beginning dissolving temperature of the lattice. It has been suggested that this system be kept up a vital good ways from by accurately alloying the structure with the development of the particular fortress [3]. Wheel is a round gadget so as to pivot the wheel an outside power should be applied to the hub. It is one of the most significant parts in vehicle. Wheels must be

Revised Manuscript Received on December 30, 2019.

* Correspondence Author

*E Vetre Selvan, Department of Mechanical Engineering, Sri Sairam Engineering College, Chennai-600044.India.

Email: vetre.mech@sairam.edu.in.; Mobile: 9597952929

K.Hariharan, Department of Mechanical Engineering, Sri Sairam Engineering College, Chennai-600044. India.

Email: e8me158@sairamtap.edu.in;Mobile: 9159870235

V. Jayasurya, Department of Mechanical Engineering, Sri Sairam Engineering College, Chennai-600044. India.

Email: e8me130@sairamtap.edu.in; Mobile: 9940438387

S. Jaiganesh, Department of Mechanical Engineering, Sri Sairam Engineering College, Chennai-600044. India.

Email: e8me181@sairamtap.edu.in; Mobile: 7397223864

M.V. Kaviselvan, Department of Mechanical Engineering, Sri Sairam Engineering College, Chennai-600044. India.

Email: e8me105@sairamtap.edu.in; Mobile: 6383882349

(C) The Authors. Published by Blue Eyes Intelligence Engineering and Sciences Publication (BEIESP). This is an open access article under the CC BY-NC-ND license (http://creativecommons.org/licenses/by-nc-nd/4.0/) inflexible enough to hold their shape under all activity condition. The structure of the wheel ought to be with the end goal that the tire can be fitted effectively [4]. Talked wheel was the main wheel which was presented in the wheel business, however these can be effectively eroded [5]. To defeat this composite wheel was presented. The blend of at least two metals is called composites. Amalgam wheel was presented which give more noteworthy steadiness at rapid. It has less number of spokes. The significant contrast between the spoke and composite wheel, in the spoke wheel the tubeless tire can't be obliged however in the combination wheel the tubeless tire can be effectively suited [6-8]. Composite wheels are the car wheels which are produced using a compound of aluminum or magnesium metals [9-11]. Combination wheels are varies from ordinary steel in view of light weight and better warmth conductors. The metal which doesnot contain iron substance such metal is called as non ferrous compounds. It is the compound which is usually utilized in the wheel business. The Non Ferrous Metals are Aluminum, Magnesium, Copper, Titanium, Nickel, Silicon,etc.,The Non ferrous metals has a few parameters like Style, Weight, Manufacturability and execution of the Design of the new wheel, The expense and weight of the Alloy wheel is less contrasting with the spoke wheel [12]. Aluminum is the most well-known materials which is utilized in wheel industry. It is the metal which is considered as a decent metal for the wheel business [13]. It has less weight and minimal effort contrasting with the various metals. Steel is the main metal which is utilized in Alloy wheel. Steel is a composite which is comprises of iron and carbon [14]. It has more quality however it is hard and significant expense. The heaviness of the steel is all the more high. Magnesium Alloy is the metal which is utilized rather than Steel. It has a few key properties that make us it is an alluring base metals for wheel. Magnesium Wheels are lighter weight contrasting with steel [15].

\section{MATERIALS AND METHODS}

Aluminum Alloy was dissolved in a cauldron by warming it in a heater at $850^{\circ} \mathrm{C}$ for three to four hours. The silicon carbide particles are preheated at $1000^{\circ} \mathrm{C}$ for one to two hours to make their surfaces oxidized. The Furnace temperature was first raised over the liquidus temperature of Aluminum close about $850^{\circ} \mathrm{Cto}$ liquefy the $\mathrm{Al}$ composite totally and was then chilled off just beneath the liquidus temperature to keep the slurry in Semi strong state. The stirrer instrument is utilized to blend the two stages. The stirrer component is set close to the heater and the tallness of the stirrer is balanced by changing the situation of the engine associated with the stand. The stirrer is submerged into liquid state inside the cauldron with the goal that it can give adequate vortex to blending. The stirrer is kept up at $350 \mathrm{rpm}$ by the controls of the dimmer detail.

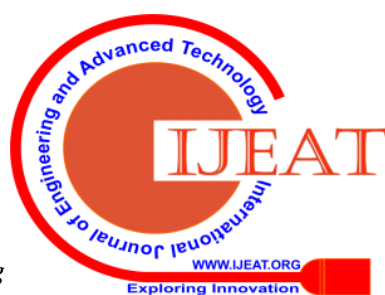


The preheated SiC particles are dropped into the cauldron in limited quantities while blending. Subsequent to enabling the particles to blend completely, the including methodology are proceeded. Finishing the expansion of $\mathrm{SiC}$ powder the mixing procedure is proceeded for 15 minutes.

The molds are prepared for throwing. The stirrer instrument is turned on till the liquid material is legitimately filled the kick the bucket by utilizing base pouring strategy. It is permitted to set for quite a while lastly evacuated to get the ideal shape.

Table 1. Composition of specimen

\begin{tabular}{|c|c|c|}
\hline & Amount of Al-7075(gm) & Amount of Sic(gm) \\
\hline Sample1 (1\%) & 762.32 & 25.54 \\
\hline Sample2 (3\%) & 824.24 & 54.31 \\
\hline Sample3 (5\%) & 828.67 & 28.42 \\
\hline Sample4 (7\%) & 801.23 & 85.78 \\
\hline
\end{tabular}
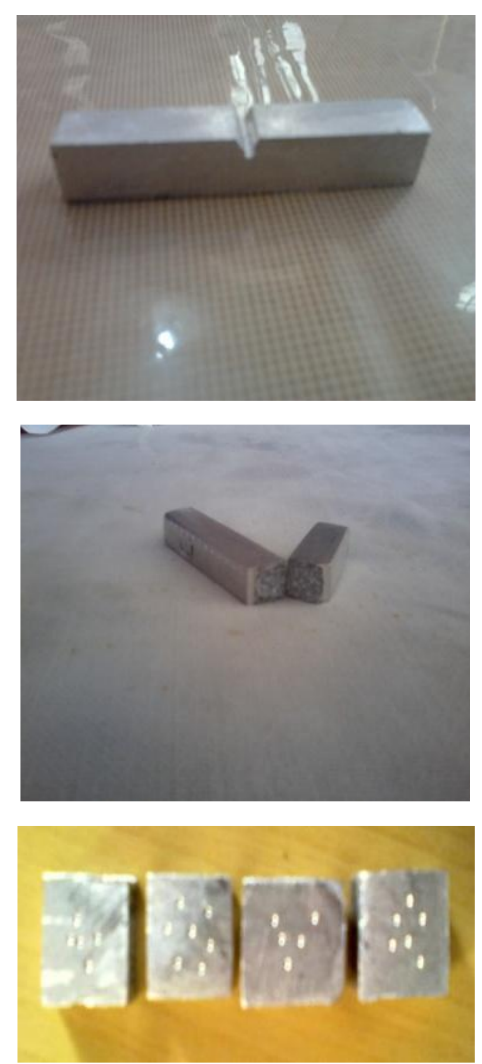

Fig 1 Test Specimen for characterization

\section{RESULTS AND COMPARISON}

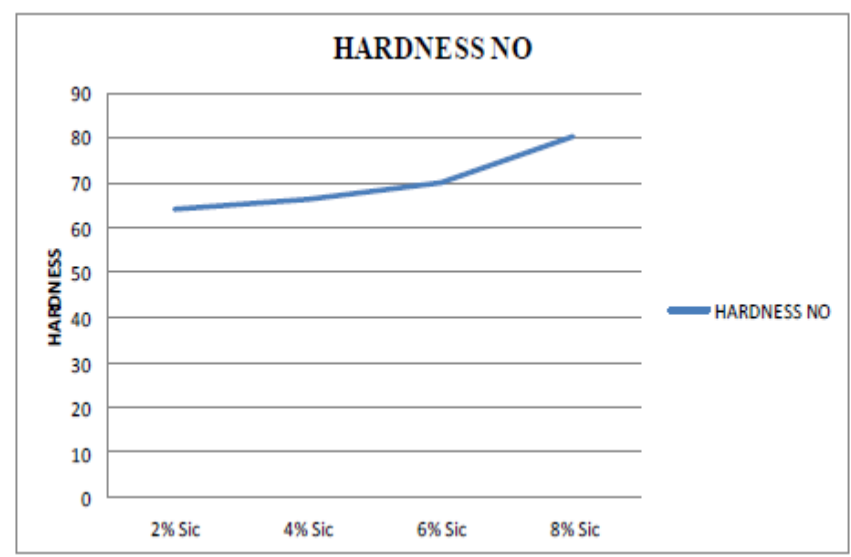

Figure 2 Hardness Result Graph

From the figure 2 it is depicted that the AA6061 with Silicon Carbide as reinforcement has an increasing hardness with respect to the increase in the weight percentage of the silicon carbide. The percentage weight of the silicon carbide of $1 \%$, $3 \%, 5 \%, 7 \%$ are having the hardness value of $64.2,66.3$, 69.9 , and 80.3 respectively.

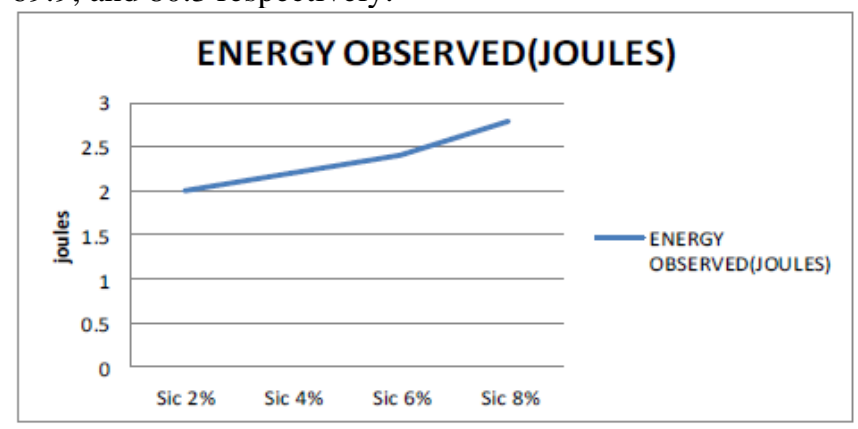

Figure 3 Impact Result Graph

From the figure 3 it is depicted that the AA6061 with Silicon Carbide as reinforcement has an increasing energy observed with respect to the increase in the weight percentage of the silicon carbide. The percentage weight of the silicon carbide of $1 \%, 3 \%, 5 \%, 7 \%$ are having the energy observed value of 2, 2.2, 2.4 and 2.8 respectively.

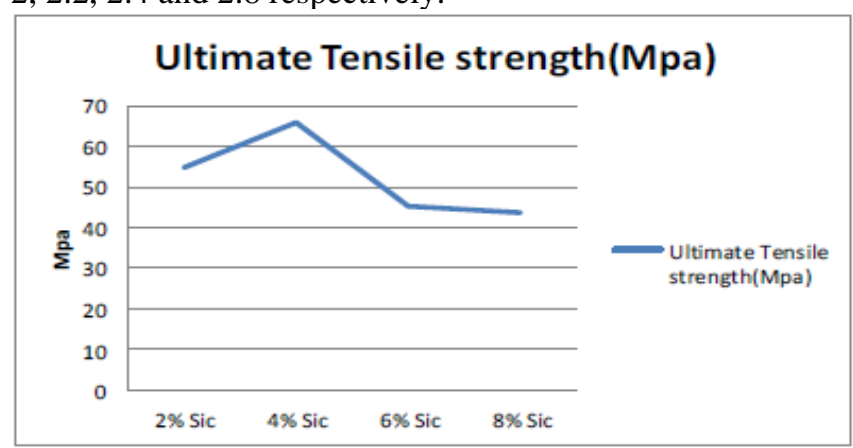

Figure 4 Tensile Strength Result Graph

From the figure 4 it is depicted that the AA6061 with Silicon Carbide as reinforcement has a decreasing Ultimate Tensile strength with respect to the increase in the weight percentage of the silicon carbide. The percentage weight of the silicon carbide of $1 \%, 3 \%, 5 \%, 7 \%$ are having the energy observed value of 54.62, 65.82, 45.32, and 43.54 respectively.

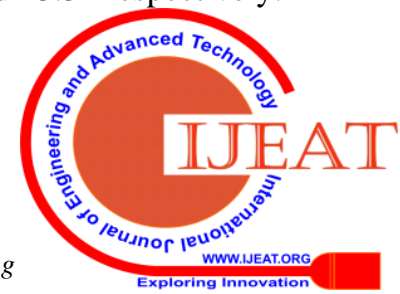


Table 2 Result Comparison

\begin{tabular}{|c|c|c|c|}
\hline Sample & $\begin{array}{c}\text { Hardness test(HV } \\
5 \mathrm{~kg})\end{array}$ & $\begin{array}{c}\text { Impact Test(Joules) } \\
\text { Ultimate load } \\
\text { test(Mpa) }\end{array}$ \\
\hline $\begin{array}{c}\mathrm{AA} 6061+ \\
1 \% \mathrm{Sic}\end{array}$ & 64.2 & 2.0 & 54.62 \\
\hline $\begin{array}{c}\mathrm{AA} 6061+ \\
3 \% \mathrm{Sic}\end{array}$ & 66.3 & 2.2 & 65.82 \\
\hline $\mathrm{AA6061+}$ & & & \\
$5 \% \mathrm{Sic}$ & 69.9 & 2.4 & 45.32 \\
\hline $\mathrm{AA6061+}$ & & & 43.54 \\
$7 \% \mathrm{Sic}$ & 80.3 & 2.8 & \\
\hline
\end{tabular}

\section{CONCLUSION}

The ends drawn from the present examination are as per the following:

1. Scattering of $\mathrm{SiC}$ particles in aluminum lattice improves the hardness of the framework material

2. It is discovered that prolongation will in general lessening with expanding particles weight. rate, which affirms that silicon carbide expansion expands fragility.

3. It shows up from this investigation that Ultimate elasticity and Yield quality pattern begins increments with increment in weight level of $\mathrm{SiC}$ in the lattice.

4. There is a negligible increment in the effect quality of the AA 6061 Silicon carbide composite as for the weight rate.

5. Mix throwing process, stirrer structure and position, blending rate and time, molecule preheating temperature, molecule joining rate and so on are seen as significant procedure parameters to decide the qualities of the example got.

6. Throwing abandons like Blow gaps, Rat tail, Porous can be handled by cleaning the form, fixing mold more tightly, utilizing vacuum chamber, keeping up temperature of liquid metal till arriving at shape.

\section{REFERENCES}

1. M. D. Vijayakumar, et.al., Mat Today:Proc., https://doi.org/10.1016/j.matpr.2019.07.741.

2. T. Adithiyaa et.al., Mat Today: Proc:, https://doi.org/10.1016/j.matpr.2019.07.711.

3. K. Gurusami, D. et al., Mat Today: Proc., https://doi.org/10.1016/j.matpr.2019.09.141.

4. K Gurusami, et.al. (2019): Int. J. Amb. Energy, DOI: 10.1080/01430750.2019.1614987.

5. Sathish,T. IJMPERDSPL201883, 2018, pp. 705-710.

6. Sathish, T. IJRTE, Volume 7 (6), 2019, pp. 281-286.

7. D Chandramohan, Acad. J. of Mfg. Eng.,12(3),2014, pp. 72-77.

8. D Chandramohan, Acad. J. of Mfg. Eng.,12(3),2014, pp. 67-71.

9. Sathish, T. IJRTE, Volume 7 (6), 2019, pp. 287-290.

10.Dhanashekar, M., et.al. Materiali in tehnologije / Materials and technology, doi:10.17222/mit.2018.038.

11.Dhanashekar, M., Senthil Kumar, VS, Tribological behaviour of squeeze cast $\mathrm{Al}-\mathrm{Si} \mathrm{Mg} / \mathrm{SiC} / \mathrm{Gr}$ hybrid composites, Journal of the Balkan Tribological Association, 24(1), 2018, pp. 106-121.

12.Dhanashekar, M., Senthil Kumar, VS, Materials Science (MEDŽIAGOTYRA), https://doi.org/10.5755/j01.ms.25.3.20442.

13.Senthil Kumar, VS., Dhanashekar, M., Karthikeyan, S, "Investigation of process parameters on dry sliding wear of self-lubricating metal matrix composites" ASME-IMECE, vol.12, 2018.

14.Mukilan. B, Arun Kumar. J, M. Dhanashekar, "Tribology Studies in Powder Metallurgy AL-LM13 SiC Reinforced Functionally Graded Composites", International Journal of Advanced Research Trends in
Engineering and Technology (IJARTET), 4(19), 2017, pp. 523-536. 15.M. Dhanashekar, V. S. Senthil Kumar, Procedia Engineering, https://doi.org/10.1016/j.proeng.2014.12.265.

\section{AUTHOR PROFILE}

Mr. E Vetre Selvan, was born in Salem ,
Tamilnadu. He received his B.E. degree in
Mechanical Engineering from SSM college of
engineering, kumarapalayam in 2010 and
M.E. in CAD/CAM from Sri Sairam
Engineering college, Chennai in 2013. He is
Working as Assistant Professor of
Department of Mechanical Engineering in Sri
Sairam Engineering college, Chennai. He has
got teaching experience of more than 6 years
and he has published various national and
international journals.

